\title{
La puerta de España de Orán. Poder y símbolo en la frontera norteafricana ${ }^{1}$
}

\author{
Antonio Bravo Nieto \\ UNED \\ Sergio Ramírez González \\ Universidad de Málaga
}

RESUMEN

La construcción de conjuntos fortificados en el norte de África durante el siglo XVI fue una de las consecuencias más visibles de la política mediterránea de los Habsburgo hispanos, destacando por su valor los realizados en Orán. Su relevancia para la corona española fue decisiva y propició la erección de la denominada puerta de España, una de las obras más emblemáticas del periodo en la que se labró una apreciable portada de tradición renacentista. A pesar de su notabilidad dentro del patrimonio oranés, la historia constructiva de esta puerta se ha mantenido hasta el momento llena de incertidumbres y falta de un estudio global. El presente artículo pretende aportar una nueva interpretación de esta estructura, contrastando los análisis extraídos de diferentes fuentes escritas y cartográficas, amén del trabajo de campo, para de esta forma ofrecer una secuencia cronológica de su fábrica y la explicación de sus principales elementos simbólicos.

\section{PALABRAS CLAVE}

Norte de África, Orán, arquitectura militar, fortificaciones, Argelia.

\section{The Spanish door of Oran. Power and symbol on the north african border}

\section{ABSTRACT}

The construction of fortified complexes in North Africa during the 16th century was one of the most visible consequences of the policy of the Spanish Habsburgs in the Mediterranean, highlighting the importance of those undertaken in Oran. It will be precisely in this city, where one of the most emblematic facades of such companies will be erected, the so-called Puerta de España, whose constructive history has remained so far full of uncertainties and the lack of a global study. The present work aims to provide a new interpretation of this monumental structure, adding the analyzes extracted from different archive sources, both written and cartographic, and from the work carried out on the same monument, offering a chronological sequence of its factory and the explanation of its main symbolic elements.

\section{KEYWORDS}

North Africa, Oran, military architecture, fortifications, Algeria. ${ }^{1}$

\footnotetext{
El presente artículo se ha elaborado en el marco del proyecto I+D "El dibujante ingeniero al servicio de la monarquía hispánica. Siglos XVI-XVIII: ciudad e ingeniería en el Mediterráneo”, ref. HAR2016-78098-P (AEI/FEDER, UE), financiado por la Agencia Estatal de Investigación (Ministerio de Economía, Industria y Competitividad) y el Fondo Europeo de Desarrollo Regional (FEDER). El trabajo de campo en Orán fue realizado junto al investigador Kouider Metair, a quien agradecemos su colaboración.
} 
1. Las portadas norteafricanas, reflejos de poder y emblemas de prestigio en zona de frontera

La construcción de fortificaciones en las ciudades del norte de África fue una herramienta primordial en el conflicto que, a lo largo del siglo XVI, se produce entre España y el imperio otomano ${ }^{1}$. En las ciudades de este territorio se llevaron a cabo ingentes trabajos encaminados a garantizar la defensa, al tiempo que destacaba su carácter simbólico bajo la materialización del concepto de frontera de una forma visible $\mathrm{y}$ disuasoria.

Si existe una parte de cualquier arquitectura militar que revista un especial carácter emblemático y estético, como memoria de su fábrica y promotores, esa no es otra que la portada principal de acceso. Es por todos sabido que durante el siglo XVI existió una amplia difusión de tales estructuras con representaciones heráldicas hispanas, tanto en la propia Península (muchas de ellas ligadas a reformas o intervenciones en murallas y recintos de origen musulmán) como en el Mediterráneo. Valga de ejemplo la construcción de notables obras en la conflictiva frontera norteafricana, cuyos motivos heráldicos y lápidas con leyendas reforzaban su trascendental funcionalidad. En este sentido, la llamada puerta de España de Orán se revela como un caso modélico, al convertirse en un importantísimo emblema del poder que la erigió.

No obstante, el paso del tiempo, la ocupación otomana que sucedió a la presencia española en algunas de estas ciudades o los avatares que sufrieron tales construcciones con la expansión colonial de otros países europeos en los siglos XIX y XX, ha desdibujado en parte su diseño original.

De la época del emperador Carlos son las portadas del castillo de España de Trípoli, de la alcazaba de Bugía y de la puerta de Santiago de Melilla. Trípoli, conquistada desde la época del rey Fernando el Católico (al igual que Bugía), recibiría una importante actuación en tiempo del emperador, materializada en el trabajo de los ingenieros Francesco de Falco, Antonio To-

GARCÍA FIGUERAS, Tomás, Presencia de España en Berbería Central y Oriental. Tremecén-Argel, Túnez, Trípoli, Editora Nacional, Madrid, 1943. masello o el florentino Piccino ${ }^{2}$, aunque los trabajos continuaron hasta $1550^{3}$. La puerta principal del castillo aparece ya dibujada en varias representaciones de mediados del siglo XVI, conforme a un esquema monumental extraído de modelos tratadísticos, con una conservación actual que presenta huellas de las intervenciones llevadas a cabo en el siglo $\mathrm{XX}^{4}$.

Por su parte, la puerta de la alcazaba de Bugía sería construida por el ingeniero Luis Pizaño en 1541, dotada de dos lápidas que recuerdan la conquista de la ciudad por Fernando el Católico y el impulso que le imprimiera a sus obras de fortificación el propio emperador Carlos $^{5}$. Aunque no se conserva el escudo de armas, sí se mantiene la totalidad de sus elementos ornamentales que responden a formas del último Renacimiento.

De mayor envergadura resulta la puerta de Santiago de Melilla, realizada por Miguel de Perea entre 1549 y $1551^{6}$, y que cuenta con un gran escudo de Carlos V dotado de águila bicéfala, toisón de oro y corona imperial, mientras que en su interior figuran todas las posesiones europeas del emperador ${ }^{7}$. Situada entre dos cubos, la portada forma un conjunto defensivo

SPITERI, Stephen, Fortresses of the Knights, Book Distributors Limited, Malta, 2001, p. 220; CASTRO FERNÁNDEZ, José Javier y CASTRO DÍEZ, Irene, "El proyecto imperial de fortificación para Bugía. 1541", en Defensive architecture of the Mediterranean. XV to XVIII centuries, vol I, Universidad Politécnica, Valencia, 2015, pp. 41-42; CASTRO FERNÁNDEZ, José Javier y CUADRADO BASA, África, "Las fortificaciones de la corona hispánica en el Mediterráneo durante los siglos XVI y XVII (1492-1700)", en IV Congreso de Castellología, Asociación Española de Amigos de los Castillos, Madrid, 2012, pp. 57-74.

3 MARINO, Angela, "Il castelo e la fortificazione di Tripoli nel Mediterraneo del'500", en Ricerche di storia dell'arte, 86, Roma, 2005, pp. 27-38.

4 AURIGEMMA, Salvatore, "Le fortificazioni di Tripoli in antiche vedute del seicento e del settecento", en Rivista delle Colonie Italiane, III, 11, Roma, 1929, pp. 11041128 y III, 12, pp. 1217-1237; GAETA, Alessandro, “A tutela et defensa di quisto regno". Il castello a mare di Palermo, Baldiri Meteli e le fortificazioni regie in Sicilia nell'età di Ferdinando il Cattolico (1479-1546), Qanat, Palermo, 2010, p. 376; MARINO, Angela, "Il castelo e la fortificazione", opus cit., pp. 27-38.

5 CASTRO FERNÁNDEZ, José Javier y CASTRO DÍEZ, Irene, "El proyecto imperial", opus cit., pp. 41-42.

6 BRAVO NIETO, Antonio, Ingenieros militares en Melilla. Teoría y práctica de fortificación durante la Edad Moderna, UNED, Melilla, 1991.

7 BRAVO NIETO, Antonio, "Tradición y modernidad en el Renacimiento español: la puerta y capilla de Santiago de Melilla", en Akros, la revista del Museo, 1, Melilla, 2002, pp. 37-41. 
de mayor complejidad, el cual comprendía una obra avanzada, una segunda puerta blasonada con otro elemento heráldico imperial y una capilla cubierta por bóveda gótica de terceletes.

De época de Felipe II son las puertas de San Antonio del peñón de Vélez de la Gomera y las de la fortaleza de Mazalquivir. La reconquista del peñón en 1564 fue una de las acciones militares más celebradas del reinado del monarca, y en sus obras de fortificación intervinieron ingenieros como Chapin Vitelli y Agustín Amodeo ${ }^{8}$. La puerta de San Antonio, construida en su totalidad de ladrillo, como la de Bugía, expone una estructura bastante arcaizante, aunque exigida por el propio terreno, en tanto queda formada por un cubo o cuerpo prismático que se apoya sobre la muralla. Lamentablemente ha perdido sus elementos decorativos heráldicos originales.

Mazalquivir, construida por el ingeniero Juan Bautista Antonelli y posteriormente ampliada por Giacomo Palearo Fratín, contó con una serie de puertas que manifestaban un sustancial conjunto de motivos heráldicos y de placas conmemorativas que exaltaban la figura del rey Felipe II, y su decisión de levantar la fortaleza. Tales testimonios permanecen actualmente muy deteriorados unos y transformados otros por obras efectuadas ya en el siglo XVIII ${ }^{9}$.

Del conjunto de puertas que acabamos de exponer se aprecia que realmente no hubo un único modelo, ni tipológico ni estético, a la hora de levantarlas. Por ello, muestran un abanico de opciones que van desde la factura más medieval en la puerta de San Antonio de Vélez de la Gomera (bajo la utilización de estructuras arcaicas como la buhedera), o el de transición en la de Santiago de Melilla (obra avanzada con casamata), hasta los prototipos de Trípoli, Bugía o Mazalquivir que contaban con puertas abiertas en la muralla y defendidas por los orejones de sus baluartes. Esta misma evolución

BRAVO NIETO, Antonio y BELLVER GARRIDO, Juan Antonio, El Peñón de Vélez de la Gomera: historia, cultura y sociedad en la España norteafricana, Fundación GASELEC, Melilla, 2008.

9 CÁMARA MUÑOZ, Alicia, "Leonardo Turriano al servicio de la Corona de Castilla", en Leonardo Turriano ingeniero del Rey, Fundación Juanelo Turriano, Madrid, 2010, pp. 15-117; BRAVO NIETO, Antonio y RAMÍREZ GONZÁLEZ, Sergio, "El sistema de puertas de la fortaleza de Mazalquivir (ريبكال|ىسرد), Argelia, durante el reinado de Felipe II", en Al-Sâbîl: Revue d'Histoire, d'Archéologie et d'Architecture Maghrébines, 9, Manouba, 2020, pp. 1-26. se aprecia en los aspectos formales, que arrancan de fuentes medievalizantes en las primeras, para llevarnos en los últimos casos a prototipos de raigambre manierista. Sin embargo, serán los elementos heráldicos y las inscripciones las que consigan dotar al conjunto de un potente significado unitario.

\section{De puerta de Tremecén a puerta de}

España: aclarando una confusión

De todo este repertorio de portadas destaca por su monumentalidad la denominada puerta de España en la ciudad argelina de Orán. Su programa estético y simbólico intentó reflejar ante todo el prestigio de la corona, erigiéndose en la antesala que recibía a las embajadas procedentes del reino de Tremecén ${ }^{10}$, obligadas a pasar por ella para acceder al palacio del gobernador de la ciudad.

La puerta es un conjunto arquitectónico de cierta complejidad resultado de las intervenciones que sufre a lo largo del siglo XVI y primeros años del XVII. Sin embargo, su historia constructiva se inicia realmente a partir de la puerta islámica de la ciudad amurallada de Orán, una de las dos con que contaba esta capital y de la que partía el camino hacia el interior del reino. Por esta razón, la que hoy llamamos puerta de España fue conocida a lo largo de todo este periodo como puerta de Tremecén, aspecto que ha pasado desapercibido para la historiografía específica de la ciudad.

Será a mediados de la segunda mitad del siglo XVII (1656) cuando se amplíe el circuito murado de Orán en su ángulo sureste, añadiendo una nueva estructura defensiva que buscaba reforzar esta entrada a la ciudad. Como consecuencia, se levantó una muralla por delante del ángulo donde se ubica la referida puerta, perdiendo su carácter original de primer ingreso y pasando a convertirse en una arquitectura intramuros. Fue también entonces cuando tiene origen la confusión sobre su denominación, de modo que sería referida durante el siglo XVIII como puerta interior, segunda o última de Tremecén, y ya desde el XIX puerta de España. De esta manera, la nueva obra arquitectonica que había sido levantada en 1656 sería conocida desde entonces, en todos los documentos, como

\footnotetext{
10 Tremecén es la forma habitual por la que se conoce a la ciudad de Tlemcen, ن اسملت.
} 
puerta de Tremecén, título que conservan sus restos en la actualidad.

Esta y otras razones, que abordaremos más adelante, han dificultado hasta el momento un correcto análisis y datación de la fábrica de la puerta objeto de nuestro estudio. En 1867 Ximénez de Sandoval ${ }^{11}$ fijaba su construcción entre 1529 y 1534. A mediados del siglo XX Eugène Cruck ${ }^{12}$ la fecharía en 1589 y, más recientemente, Mohamed Amine Khelifa ${ }^{13}$ ha señalado su correspondencia con el gobierno del marqués de Ardales y la data en 1605. Como explicaremos más adelante, todos tienen algo de razón.

\section{La emperatriz Isabel y Hernando de Quesada}

Desde que el cardenal Cisneros conquistara Orán en 1509, uno de sus principales objetivos consistió en reforzar las defensas de la ciudad, incluidos los sistemas fortificados de sus puertas, contando con Diego de Vera en estos primeros años para la dirección de los trabajos.

Cuando en mayo de 1529 Jeireddin Barbarroja asaltó y destruyó la fortaleza española del peñón de Argel, se temió que el almirante turco expandiera sus conquistas por el norte de África, en tanto acometía la expulsión de los españoles de sus costas. La ciudad de Orán, entonces bajo el gobierno del marqués de Comares, se sintió directamente amenazada y, por esta razón, el 16 de octubre de ese mismo año, la emperatriz Isabel ordenaba fortificarla ${ }^{14}$.

Para analizar el estado de las defensas y poder planificar los trabajos necesarios se designó a una persona de gran prestigio, Per Afán de Ribera, cuya presencia en Orán ilustra los temores de la emperatriz sobre la posibilidad de un ataque, de ahí que le pidieran que examina-

11 XIMÉNEZ DE SANDOVAL, Crispín, Las inscripciones de Orán y Mazalquivir: noticias históricas sobre ambas plazas desde la conquista hasta su abandono en 1792, Establecimiento Tipográfico de R. Vicente, Madrid, 1867, pp. 16-17.

12 CRUCK, Eugène, Oran et les témoins de son passé, Heinz fréres, Orán, 1956, pp. 16-18.

13 KHELIFA, Mohamed Amine, Monarquía de España siglos XVI-XVIII: evolución cronológica del sistema defensivo de Orán y Mazalquivir. Archivo de la Frontera, 2015, pp. 36-38.

14 DIDIER, Léon, Histoire d'Oran, par le Général ... Période de 1501 a 1550, Imprimerie Jeanne D’Arc, Orán, 1927, pp. 147 y $149-150$. se las obras y diseñara el plan y los pasos oportunos a seguir ${ }^{15}$. A partir de sus indicaciones la corte decidió reformar la alcazaba.

Las obras ya debían haber comenzado para el 6 de diciembre, cuando se le ordenó al corregidor de Orán que la gente de guerra, además de los obreros especializados, trabajase en ellas ${ }^{16}$. José Aparici (1851) señala que el capitán de azadoneros Hernando de Quesada fue destinado desde la Península a Orán en 1530, con el objeto de ejecutar los trabajos de fortificación $^{17}$. Dicho ingeniero llegaba a la cabeza de un importante número de obreros para dirigir las labores que allí se desarrollaban ${ }^{18}$. Tanto es así, que el 14 de septiembre de 1530 se le comunicó a Juan López de Recalde, proveedor de la armada, que se enviaban "150 trabajadores, tapiadores, azadoneros y paleteros", para hacer las tapias, fosos y fortificaciones precisas ${ }^{19}$.

Las obras que habian de acometerse concernían fundamentalmente a la alcazaba y a la zona de la puerta de Tremecén. El 27 de enero de 1531 la propia emperatriz Isabel escribía: "Agora nuevamente se ha enviado a Hernando de Quesada que es ombre que tiene espiriençia en obras e edefiçios e reparos e fortificaciones, con 200 ombres azadoneros e que estos podrían reparar e fortificar todo lo que a él le parecie$\mathrm{re}^{20}$. Hernando de Quesada finaliza sus trabajos en Orán a finales de 1532, dejando las murallas de la alcazaba en buen estado de defensa, con la construcción de alguna torre y la adaptación artillera de sus cortinas y puerta. Este es el es-

Archivo General de Simancas (AGS), Reg. del Consejo, libro IV, fol. 42 v., memorial de 11 de noviembre de 1529 (Aparici, Biblioteca Central Militar [BCM]: 69). También AGS, Reg. del Consejo, libro III, 1529 (Aparici, BCM: 69).

16 AGS, Reg. del Consejo, libro III, 1529, fols. 18-19 (Aparici, BCM: 69); XIMÉNEZ DE SANDOVAL, Crispín, Las inscripciones de Orán, opus cit., p. 16.

17 APARICI GARCÍA, José, Continuación del informe sobre los adelantos de la Comisión de Historia en el Archivo de Simancas ... $3^{a}$ parte, trata de las biografias de ingenieros que existieron en España en el siglo XVI, Memorial de Ingenieros, 1851, p. 9.

18 AGS, Reg. del Consejo, libro III, 1530, fol. 196 (Aparici, BCM: 69)

19 AGS, Reg. del Consejo, libro III, 1530, fol. 190 v. (Aparici, BCM: 69).

20 AGS. Guerra y Marina, legajo 1317, fol. 71; GUTIÉRREZ CRUZ, Rafael, "La renuncia de un capitán general: los últimos años del gobierno del II marqués de Comares en Orán y Mazalquivir", en Los Fernández de Córdoba, nobleza, hegemonía y fama, Ayuntamiento, Alcalá la Real, 2018, pp. 191-192; DIDIER, Léon, Histoire d'Oran, opus cit., pp. 156-159. 
tado de la ciudad que conocemos merced a un informe elaborado en 1535 por Bernardino de Mendoza $^{21}$, con la descripción de sus defensas artilleras. En concreto, la puerta se encontraba protegida desde las correspondientes cañoneras de los cubos situados al este y al oeste, mientras que su propia estructura la asimilaba a una torre artillada con piezas de pequeño calibre. Aun así, las obras proseguían y tres años después encontramos trabajando en Orán a un nuevo experto en fortificaciones, Francisco de Sotomayor $^{22}$.

Con toda seguridad, en función de la importancia de esta obra y de las pautas asumidas en otras muchas fortificaciones norteafricanas, la puerta debió contar entonces con elementos representativos del emperador Carlos V, bien heráldicos o lapidarios, de ahí la posibilidad de que su configuración primitiva fuera reutilizada en las intervenciones posteriores.

\section{Los trabajos en época de Felipe II}

Este monarca heredó el interés de su padre por contener el poder marítimo del imperio otomano. Por ello, en 1563 y ante el asedio que una escuadra turca dispuso sobre Orán y Mazalquivir, Felipe II ordenó su fortificación y defensa planificando al mismo tiempo la recuperación del peñón de Vélez de la Gomera.

Mazalquivir fue totalmente reedificado, mientras que en Orán se acometieron trabajos de menor envergadura, entre los que destacaremos los emprendidos en la puerta de Tremecén. En concreto, el gobernador la reforzó con más artillería y con la construcción de una obra exterior, a describir por Pedro Salazar ${ }^{23}$ : “mandó al maestre Raphael, maestro mayor de las obras de Orán, [...] que se hiziesse un bestión de faxina a la puerta de Tremecen que abraçasse la torre que estaba cerca de ella" (p. 51), "Y el rey de Argel mandaua dar fastidio a los que labrauan a la puerta de Tremecen, a fin de que no se fortificasen" (p. 53).

Asimismo tenemos el testimonio de Diego Suárez Montañés, quien vivió en Orán en los

\footnotetext{
$21 \quad$ AGS, legajo 462 (20-12-1535); DIDIER, Léon, Histoire d'Oran, opus cit., pp. 225-232.

22 AGS, Mar y Tierra, legajo 5, 1535 (Aparici, BCM: 70).

23 SALAZAR, Pedro de, Hispania Victrix. Historia en la cual se cuentan muchas guerras sucedidas entre cristianos e infieles, Vicente de Millis, Medina del Campo, 1570.
}

últimos decenios del siglo XVI y nos confirma que la puerta de Tremecén era el lugar por donde los argelinos entraban principalmente a la ciudad $^{24}$. Suárez apunta también que se hizo un bastión o baluarte en el ángulo sur del lienzo, junto a la puerta, y que la muralla que se reparaba mantenía una sola estacada, caída varios años atrás, por lo que se trabajó en su terraplenado y talud. Resulta evidente que los trabajos anteriormente descritos buscaban reforzar la capacidad defensiva de la puerta a través de la construcción de obras exteriores.

Henry Leon Fey ${ }^{25}$ defiende que sería en el último tercio del siglo XVI cuando los trabajos en la alcazaba se efectuaron a mayor escala, algo que también documenta en 1591 el contador Diego de Arce $^{26}$. Tales obras fueron llevadas a cabo durante el gobierno del maestre de campo Pedro de Padilla y Meneses (26 de agosto de 1585 a 14 de noviembre de $1589^{27}$ ). Padilla informaba directamente a Felipe II sobre la marcha de las obras, mientras el monarca le manifestaba en una carta de enero de 1588 la necesidad de finalizarlas: "no se alce la mano de ella hasta acabarse" 28 .

Parte de estas labores se realizaron en el sector de la alcazaba más cercano a la puerta de Tremecén, donde Padilla construyó un nuevo almacén que encajaba en un espacio rectangular en el frente este, cuyo acceso tuvo que ser reformado tal y como figura en la actualidad.

Junto a la puerta principal de la real alcazaba, sobre la fachada del almacén construido por Padilla, existe una lápida de piedra con letras incisas de estaño y plomo, así como un escudo de piedra con las armas de Felipe II y el toisón de oro $^{29}$ : "EN EL AÑO D. 1589 SIN COS/TAR A SU MAGESTAD MAS / QUE EL VALOR DE LAS

24 SUÁREZ MONTAÑÉS, Diego, Historia del maestre último que fue de Montesa... (edición y estudio de Miguel A. de Bunes Ibarra y Beatriz Alonso Acero), Institució Alfons el Magnànim, Valencia, 2005, p. 320.

25 FEY, Henry-Léon, Histoire d'Oran avant, pendant et après la domination espagnole, Typographie Adolphe Perrier, Orán, 1858.

26 AGS, GA, legajo 342, fol. 313, 16 de marzo de 1591.

27 FERNÁNDEZ, Santiago, "Pedro de Padilla. Diccionario Biográfico de la Real Academia de la Historia”, en $<$ http://dbe.rah.es/biografias/30010/pedro-de-padilla> [27/5/2020].

28 Biblioteca de la Fundación Zabálburu (BFZ), carpeta 215, legajo 1-2, 8 de enero de 1588. Alonso, 1997.

29 GAVER, Antonio y MOTE, Alejandro de la, Inscripciones de Orán y Mazalquivir y catálogos de sus gobernadores (Ms.), 1746-1747, pp. 5-6 (Biblioteca Fundación Lázaro Galdiano). 
MADE/RAS HIZÓ ESTA OBRA DON / PEDRO DE PADILLA SU CA/PITAN GENERAL I JUSTI/ CIA MAYOR DE ESTAS PLA/ZAS POR SU DILIGENCIA I BU/ENOS MEDIOS".

Todas estas obras quedaron plasmadas en los planos de 1598 que trazó el ingeniero Leonardo Turriano ${ }^{30}$, en virtud de los cuales podemos apreciar la organización de la antigua puerta de Tremecén y sus murallas colindantes.

La última referencia de obras que vamos a contemplar en este recorrido cronológico data de 1605 , rematando la imagen de la puerta tal y como nos ha llegado hasta la actualidad. Todo parte de una postrera intervención documentada a mediados del siglo XVIII por Antonio de Gaver y Alejandro de La Mote ${ }^{31}$, en la que especifican la existencia de una lápida con la siguiente leyenda:

"En la puerta última de Tremecén para entrar en la plaza, al lado de la casa número $1^{\circ}$ en donde hauitaba el Ingeniero Comandante está escripta de piedra de esta cantera esta inscripción: El marqués de Ardales, conde de Theba, mariscal / de Castilla capitán general y justicia maior de / esta ciudad de Orán y villa de Mazalquivir y / reynos de Tremecén y Tenez por el rey Don Phelipe / nuestro señor tercero de este nombre, mando hacer / esta obra, año de 1605".

La referencia que hacen Gaver y La Mote posee una enorme relevancia, puesto que confirma la postrera reforma de 1605 y revela su designación a mediados del siglo XVIII como "puerta última de Tremecén", es decir, que no había perdido totalmente su nombre en aquellas fechas. Además, la ubicación no ofrece lugar a dudas al situarla con exactitud junto a la casa del ingeniero, fácilmente identificable en la cartografía del siglo XVIII. Sin embargo, ya no existía esta lápida cuando Sandoval visita Orán un siglo después; así lo atestigua el hecho de que tuviera que acudir a otras fuentes para transcribirla. El problema surge en el momento en que Sandoval (p. 37) confunde su ubicación

30 CRESPO DELGADO, Daniel, "Descripcion de las Plaças de Oran y Mazarquivir, en materia de fortificar de Leonardo Turriano", en Leonardo Turriano ingeniero del Rey, Fundación Juanelo Turriano, Madrid, 2010, pp. 229-275.

31 GAVER, Antonio y MOTE, Alejandro de la, Inscripciones de Orán, opus cit., p. 6. y sitúa la lápida en la puerta nueva de Tremecén y no donde en realidad estuvo, lo que es reproducido posteriormente por Sánchez Doncel (p. 235). Finalmente, Mohamed Amine Khelifa acepta este dato, aunque deduciendo acertadamente que se refería a la puerta de España (p. 36). Con todo, hasta el momento nadie se había percatado de que lo que hoy se conoce como puerta de Tremecén no existió hasta $1656^{32}$.

Es evidente que la obra del marqués de Ardales se realizó sobre una portada preexistente, que partiría con toda probabilidad de los trabajos desempeñados en 1530-1532. La mala calidad de la piedra utilizada tanto en Orán como en Mazalquivir provocó que algunos escudos se desdibujaran y necesitaran ser reconstruidos; ocurrió en esta última fortaleza en el mismo siglo $\mathrm{XVI}^{33} \mathrm{y}$ pensamos que también pudo darse en el caso de la puerta de Orán. Esto explicaría el hecho de que resultara más fácil la sustitución del escudo heráldico del emperador por otro de Felipe II o Felipe III. Esta teoría también deja abierta la posibilidad de que la composición general y algunos elementos ornamentales originales sí pudieran ser reaprovechados en la reforma de 1605.

\section{Tipología y estructura de la puerta}

Esta obra forma parte de un complejo conjunto defensivo, cuya función consistía en vigilar y proteger el acceso a la ciudad. Estructuralmente es un torreón prismático adosado a la muralla, provisto de una morfología que nos recuerda sus orígenes como puerta islámica. No obstante, las continuas reformas realizadas a lo largo del siglo XVI para pertrecharla desvirtuaron su carácter de vanguardia defensiva hasta convertirla en una obra interior, precedida de otras estructuras fortificadas.

Desde mediados del siglo XVII quedó establecido el recorrido definitivo de cualquier persona para ingresar en Orán. En primer lugar,

\footnotetext{
32 GAVER, Antonio y MOTE, Alejandro de la, Inscripciones de Orán, opus cit., p. 5. "En el muro frente a la entrada de la puerta de Tremecén vaxo, donde arrima las armas la guardia se ve esculpido en piedra blanca de la cantera lo siguiente: Reynando el rey nuestro señor Don Felipe IV y gobernador Antonio de Zúñiga y de la Cueva, Marqués de Flores Dávila, del consejo de guerra de S. M. se hizo esta obra, cuya importancia se ve puesto en este sitio año de 1656".

33 BRAVO NIETO, Antonio y RAMÍREZ GONZÁLEZ, Sergio, "El sistema de puertas, opus cit.
} 
se entraba en el interior del perímetro amurallado por la puerta nueva de Tremecén. A partir de aquí, daba inicio un camino ascendente encajado entre dos muros, con finalización en una puerta de arco rebajado que aún conserva vestigios de su sistema de cierre. Pasado este primer tramo era obligado tomar un ángulo de $90^{\circ}$ a la derecha, donde se abre otro arco en la misma muralla que, en su momento, correspondió con la parte más externa del conjunto tal y como la dibujó Turriano en 1598 [Fig. 1].

Atravesando la muralla se accede a un espacio rectangular a cielo abierto, en el que se sitúan, en su flanco derecho, tres grandes arcadas de medio punto en sillería, cuya función podría relacionarse con el uso como bancos para los centinelas de la guardia o, bien, para el depósito y custodia de las armas de aquellos que se disponían a entrar en la ciudad, tal como se ha documentado en construcciones similares como la puerta de la Justicia y la de Elvira de Granada $^{34}$ [Fig. 2].

En este espacio a cielo abierto se visualiza frontalmente la portada que constituye la parte más significativa del conjunto, a tenor de la magnificencia mostrada para cualquier persona que llegara a la ciudad [Fig. 3]. Dicha portada queda integrada en un macizo cuerpo en forma de cubo prismático, en cuya base se abre la bóveda de comunicación por debajo de un frontis prácticamente ocupado por la ornamentación arquitectónica y heráldica. Atravesando esta bóveda de medio cañón de sillería de trazado recto se accedía a una estancia o cuerpo de guardia (hoy desaparecido), que obligaba a realizar el recodo característico en la fortificación de puertas antes de entrar definitivamente en la ciudad.

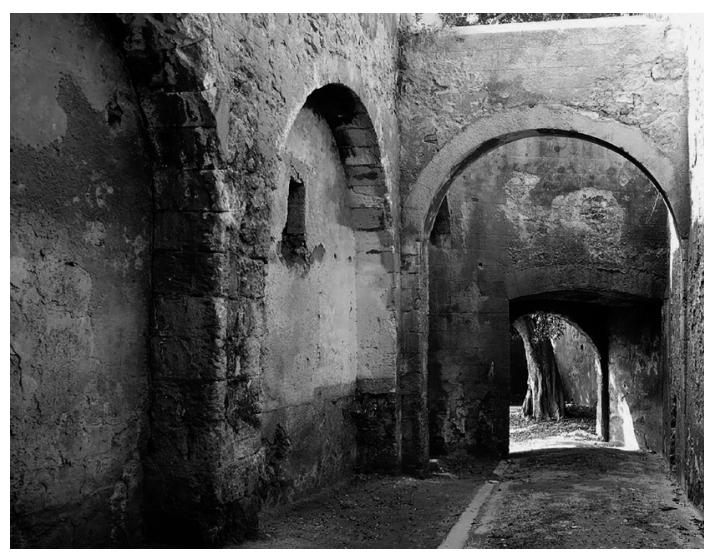

Fig. 2. Vista del espacio abierto previo a la portada, con los arcos ciegos a la izquierda y de frente, primero, la arcada transversal y, al fondo, la puerta inicial de acceso, 2012 (Fotografía Jean-Yves Thorrignac y Sydney Serra-Reich).

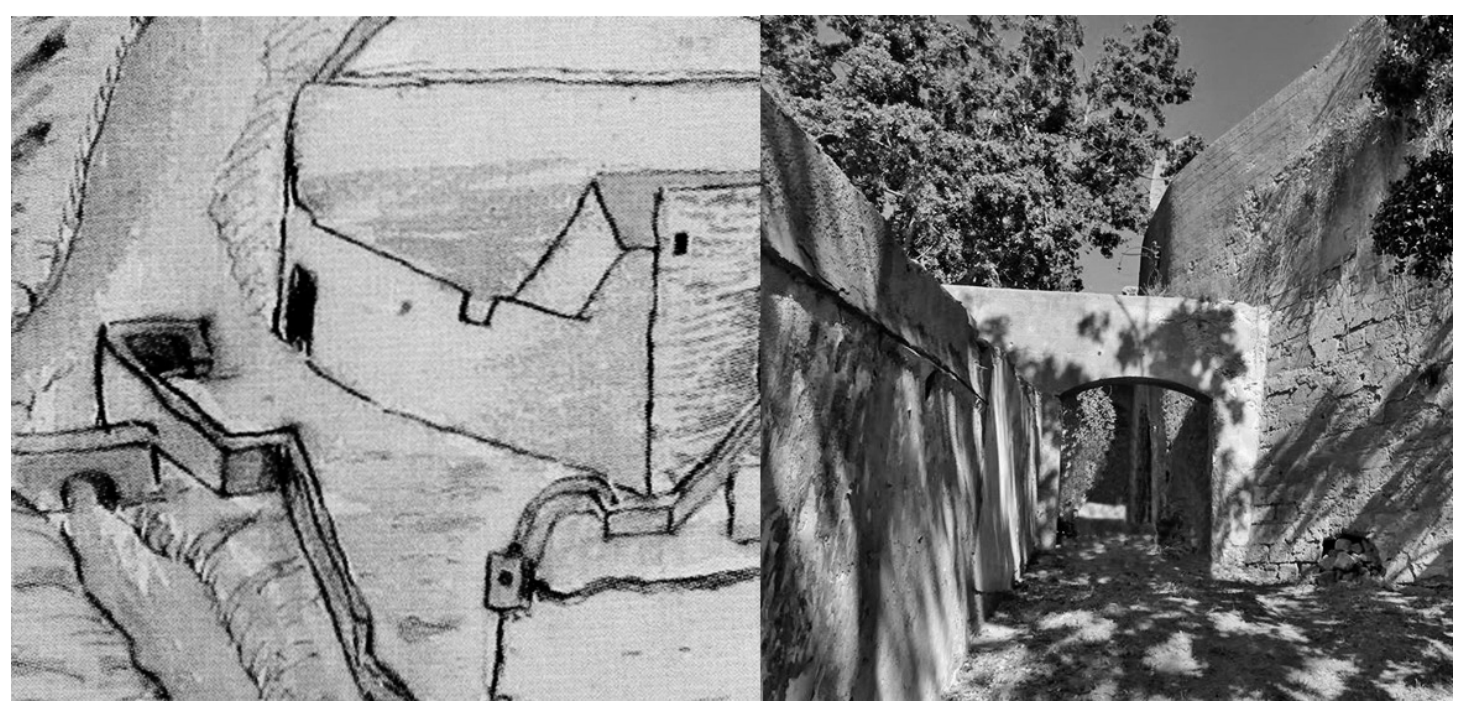

Fig. 1. Vista de la puerta exterior, al final del camino ascendente, en un dibujo de 1598 de Leonardo Turriano (Perspectiva de Orán ..., Descripción de las Plaças de Oran i Mazarquivir en materia de fortificar, 1598, Academia das Ciencias de Lisboa, Ms. Azul, $\mathrm{n}^{\circ}$ 1065, f. 15) y en 2017 (Fotografía Antonio Bravo).

34 PAVÓN MALDONADO, Basilio, Tratado de arquitectura Hispano-marroqui II. Ciudades y fortalezas, CSIC, Madrid, 1999, p. 455. 


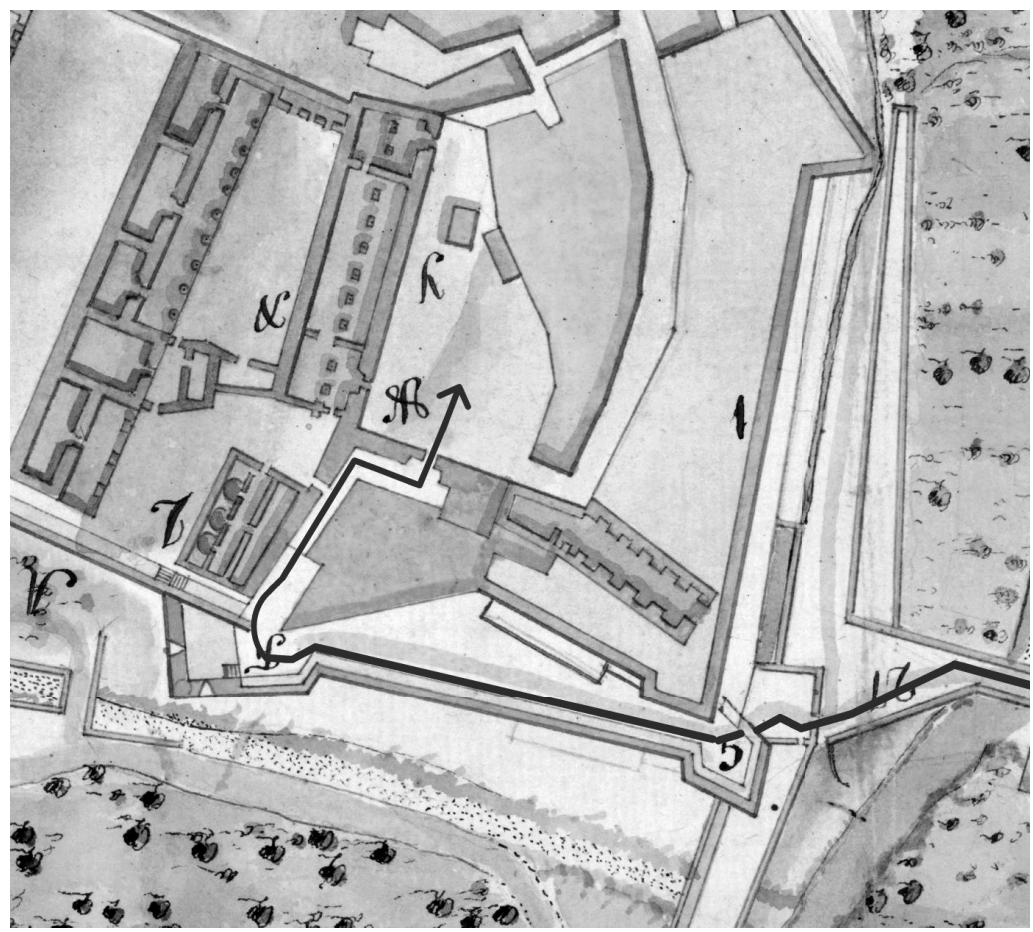

Fig. 3. Recorrido de entrada a Orán por la puerta de Tremecén y puerta de España, sobre el sector de un plano de 1736 (Centro Geográfico del Ejército, ORAN-84).

\section{Análisis de la portada}

Ya avanzamos en líneas precedentes que el conjunto conocido como puerta de España de Orán experimentó distintas reformas a lo largo del tiempo: desde su origen como entrada principal de la ciudad islámica, los trabajos realizados por Diego de Vera en los primeros momentos del siglo XVI, el programa de obras llevado a cabo por Hernando de Quesada hacia 1530-1532, las obras defensivas de la década de los sesenta, la intervención de Padilla en 1598 y la definitiva configuración dada por el marqués de Ardales en 1605.

Centrándonos en la portada, la referencia documental gráfica más antigua que conocemos data del 6 de abril de 1744, cuando el ingeniero Antonio de Gaver la dibuja en uno de sus planos $^{35}$. Allí figuran sus elementos fundamentales: los dos escudos que han llegado hasta la actualidad, en diferente estado de conservación, una amplia lápida (que es la que el propio Gaver transcribe en su trabajo ${ }^{36}$ ), y el remate ornamental actualmente desaparecido [Fig. 4].

Por su parte, las fotografías más antiguas del mismo conjunto remiten a finales del siglo

AGS, MPD, 13-147.

36 GAVER, Antonio y MOTE, Alejandro de la, Inscripciones de Orán, opus cit., pp. 5-6.
XIX, pudiéndose comprobar en ellas cómo el monumento se conservaba sin sufrir grandes cambios, aunque había perdido el referido remate decorativo y la lápida. Ya en el siglo XX las imágenes permiten apreciar ciertas intervenciones, caso de la recomposición de detalles heráldicos y arquitectónicos desaparecidos o en mal estado, lo que delata un interés a lo largo de esta centuria por su restauración, motivada por el deterioro del conjunto fruto de la meteorización de la piedra.

Como se ha señalado, la parte de mayor interés estético y artístico del conjunto es sin duda la portada. Se trata de un frontis en sillería que conjuga perfectamente las directrices estéticas italianas con esquemas de transición más retardatarios, sin perder nunca de vista los aspectos más plenamente castrenses. En definitiva, una obra que unifica el esplendor decorativo con la sobriedad monumental, y que parece acercarse mucho más a los modelos bajomedievales de las portadas tapiz que a los renacentistas de las portadas retablo.

La portada de referencia está formada por tres cuerpos, separados por cornisas, que van creciendo en sus dimensiones de manera progresiva. El primero, un rectángulo entre pilastras cajeadas, que servía de tarjeta a la puerta al insertarse en ella la desaparecida lápida de la fábrica. El segundo y tercer cuerpo se ha- 


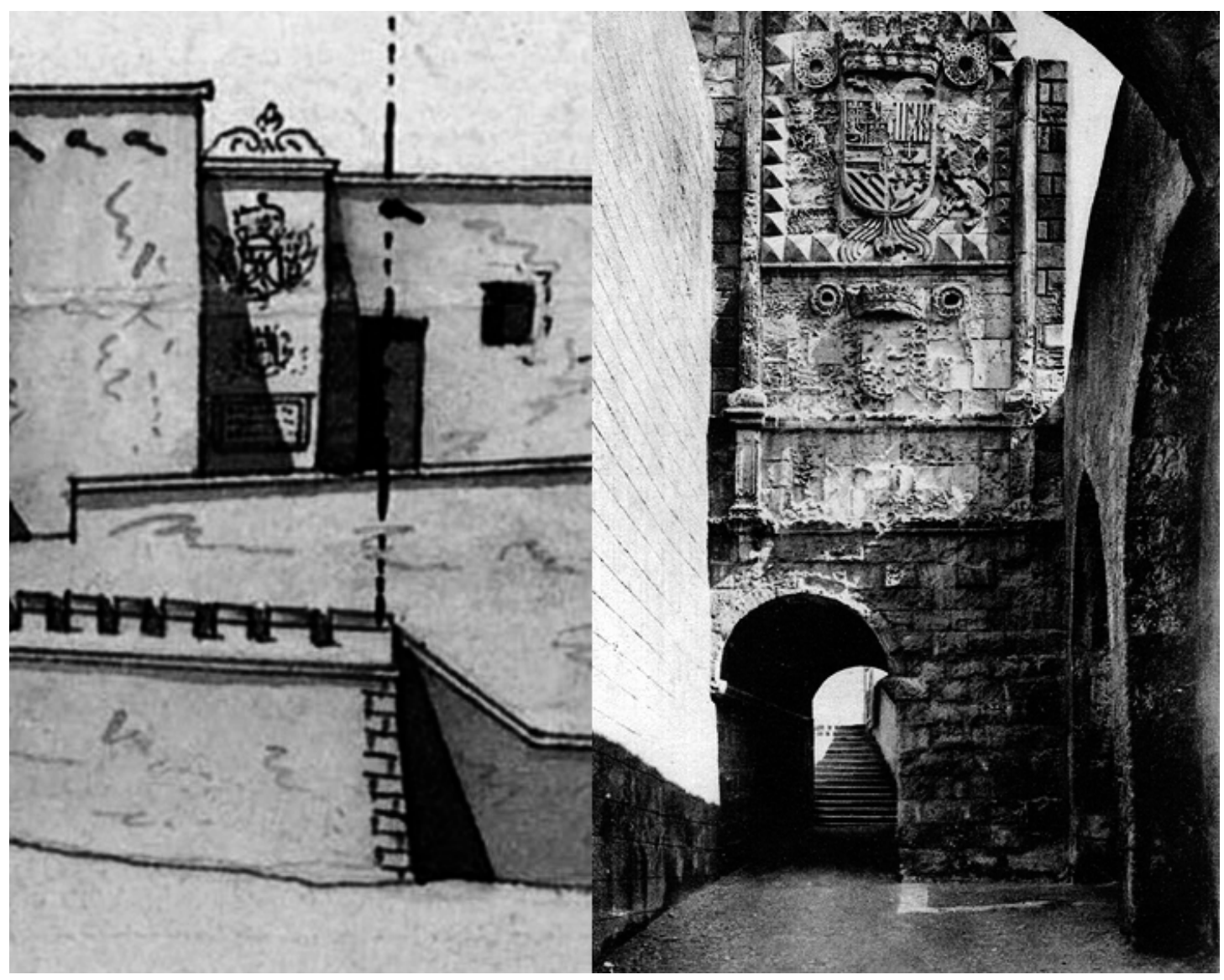

Fig. 4. Vista de la portada de la puerta de España en un dibujo de 1744 (Antonio de Gaver, AGS. MPD. 13-147) y en una fotografía de principios del siglo XX (Archivo Cronista Oficial de Melilla).

llan flanqueados por medias columnas bastante estilizadas, que responden a un orden híbrido jónico-toscano que incluye en la parte frontal un astrágalo abalaustrado, propio del capricho manierista. En resumidas cuentas, dos sectores superpuestos: uno muy desdibujado por su estado de deterioro, en el que se inserta un blasón y dos resaltes decorativos circulares, y otro donde el frontis adquiere mayor tamaño y significación alrededor de un enorme escudo que cuenta también con los referidos motivos ornamentales [Fig. 5].

Los distintos componentes encuentran un complemento estético perfecto a partir del almohadillado de puntas de diamantes; elementos de enorme trascendencia medievalizante, que van a estar estrechamente vinculados a la arquitectura militar y civil durante el Renacimiento. Su utilización quedará presente en fortalezas y palacios de la segunda mitad del siglo XV y primera del XVI, con especial predicamento en Italia donde encontramos como destacados exponentes el Palacio dei Diamanti de Ferrara, el bastión central de la fortaleza de Florencia, el Castel Gavone en Finalborgo (Liguria) y la iglesia del Gesù Nuovo de Nápoles, anteriormente Palacio Sanseverino ${ }^{37}$.

Fundamental para la puesta en práctica de tales elementos fueron los tratados de arquitectura; en nuestro caso, de arquitectura militar como el que efectuase Francesco di Giorgio, quien no solo lo recomienda a través de los dibujos de los muros de castillos, sino que lo emplea, de un modo ciertamente caprichoso, en la cubierta de una galería porticada inserta en la pintura Ciudad ideal (h. 1495), de la Gemäldegalerie de Berlín. Es más, en su faceta más pragmática, en lo que a la defensa se refiere, añade que tales motivos servían para dificultar la escalada de las murallas y torreones, sobre

37 PLAZA MORILLO, Carlos, “Arquitectura militar en Italia en el siglo XVI y la aportación española: el caso de Florencia y Siena”, en Actas del VII Congreso Nacional de Historia de la Construcción, Instituto Juan de Herrera, Madrid, 2011, pp. 1133-1146. 


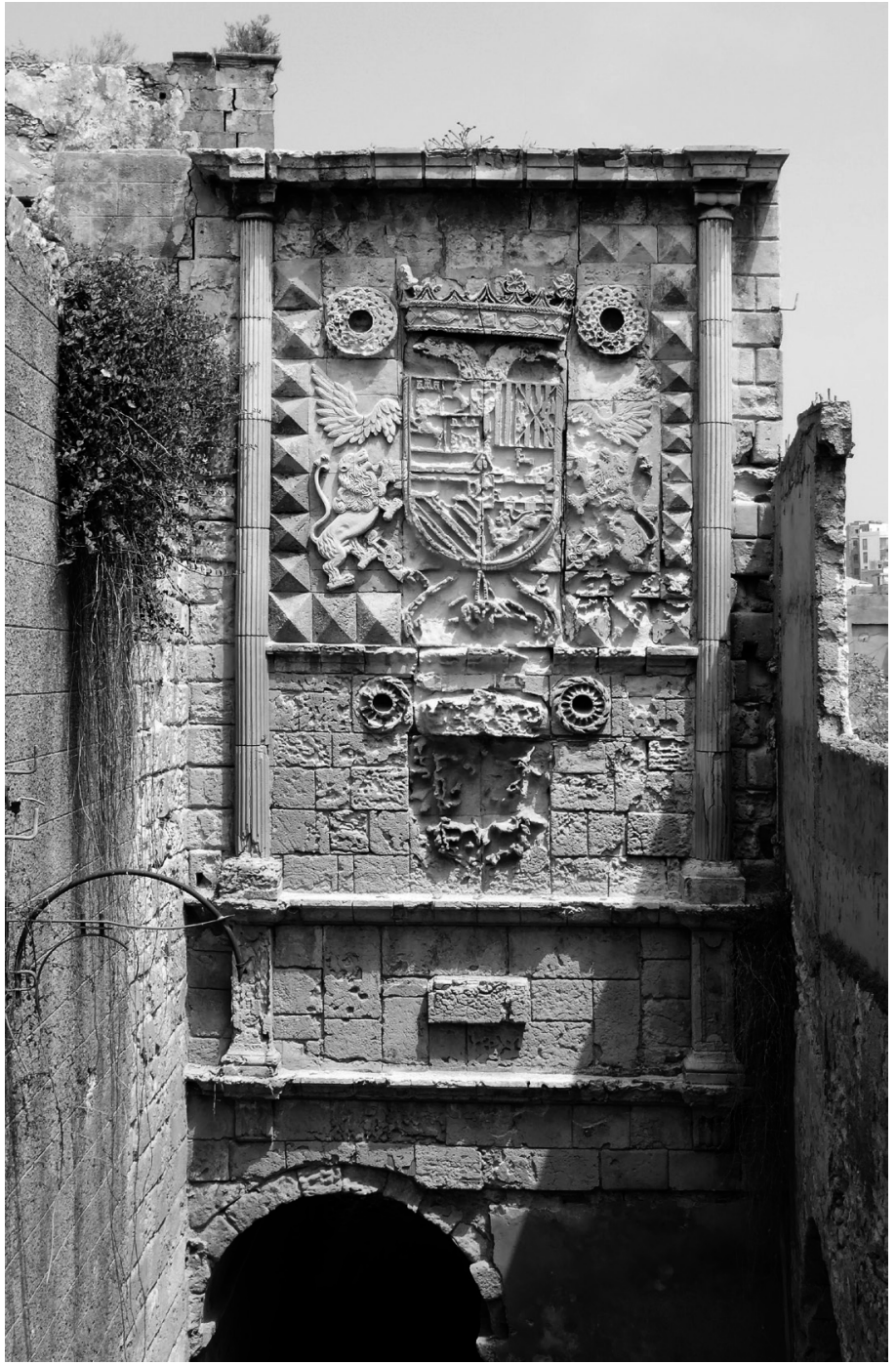

Fig. 5 Vista actual de la portada de la puerta de España de Orán (Fotografía de Antonio Bravo, 2019).

las denominadas como puntas de diamantes al tresbolillo ${ }^{38}$. El propio Sebastiano Serlio dedicó atención a estos motivos en su tratado, dentro del apartado dedicado al orden rústico, haciendo hincapié en su evolución a lo largo del tiempo y las tipologías en los que había derivado. Sin desdeñar, las referencias también ofrecidas por Baldassare Peruzzi en su Trattato di architettura militare.

Si en Italia llegaron a alcanzar una considerable extensión, en España tuvieron una más puntual presencia en los exteriores de palacios y castillos-palacio de la etapa de transición y del primer Renacimiento, aunque pudo dar-

38 VERA BOTÍ, Alfredo, La arquitectura militar del Renacimiento a través de los tratadistas de los siglos XV y $X V I$ (tesis doctoral), Universidad Politécnica, Valencia, 2001, pp. 549-550. se puntualmente con un mayor retraso. Valga nombrar los ejemplos del palacio de Jabalquinto, el castillo de los Mendoza en Manzanares, la casa de los Picos de Segovia y el palacio del Infantado de Guadalajara, entre otros.

En definitiva, que, aunque puede llegar a alcanzar alguna función práctica, su utilización parte de la arquitectura militar para llegar a la civil y convertirse en un mero elemento decorativo, si bien representando de manera emblemática lo férreo e inaccesible, un poder magnificado que incide asimismo en lo disuasorio.

En otro orden de cosas, los elementos ornamentales y heráldicos del conjunto nos plantean una serie de interrogantes, tanto por su alterado acoplo como por el mal estado de conservación que presentan. Su propio ajuste en la portada es uno de ellos, ya que las piezas de sillería se encuentran muy mal engarzadas e incurren 
en graves errores de encaje. Algo que delata el montaje poco cuidadoso o la recomposición del escudo, lo que explicaría los problemas de simetría y desequilibrio que observamos entre sus piezas. A pesar de esa probable renovación habría conservado el marco y el esquema original, como demuestra Daniel Domenech Muñoz en su estudio sobre las proporciones de la por$\operatorname{tada}^{39}$. Para este autor la fachada se compone de dos cuadrados idénticos más la proporción áurea de uno de ellos (en rojo, comprendiendo el remate desaparecido) [Fig. 6 A]. Por su parte, en el cuadrado inferior, la línea de imposta del arco que forma la bóveda de la puerta, determina la mitad de su altura y la luz la mitad de su ancho. Igualmente aprecia que la composición enmarcada entre las dos columnas está formada por sendos cuadrados, a situar uno sobre el otro (en naranja). Los referidos cuadrados interiores entre columnas están en relación directa con el cuadrado exterior de la composición general, en una proporción raíz de dos, a saber, uno es 1,414 veces más grande que el otro, tal y como puede apreciarse en la citada figura.

Por otro lado [Fig. 6 B], si nos ceñimos al análisis específico de los elementos heráldicos y los bajorrelieves situados entre las columnas, se observa que esta estructura de dos cuadra- dos puede descomponerse verticalmente en segmentos derivados de la proporción raíz de 2 y áurea de este cuadrado. Así, entre la cornisa A y $\mathrm{B}$, encontramos un segmento de raíz de 2 $(0,414)$; entre la B y la C, el segmento áureo $(0,618)$; y entre C y D, un cuadrado (1). A su vez, el escudo, leones y alas del cuadrado superior, coincide con el segmento áureo, mientras que verticalmente los escudos ocupan un ancho de 0,414 veces el lado del cuadrado. Por último, según Domenech, los resaltes decorativos circulares se localizan mediante el punto de corte de las diagonales entre extremos de cornisas opuestas y las diagonales de los rectángulos que quedan a cada lado de los escudos.

Todas estas características apuntan a una fábrica unitaria, donde se descarta el hecho de que la portada sea el resultado de diferentes alteraciones generales posteriores. En otras palabras, que las actuaciones sobre ella siempre han respetado su estructura general, centrándose, todo lo más, en la sustitución de elementos ornamentales concretos o en recomposiciones derivadas de accidentes, caso de las consecuencias de un terremoto.

En el escudo aparecen representadas las diferentes posesiones de los Habsburgo a partir de Carlos $\mathrm{V}$ y que se consolida en un mismo

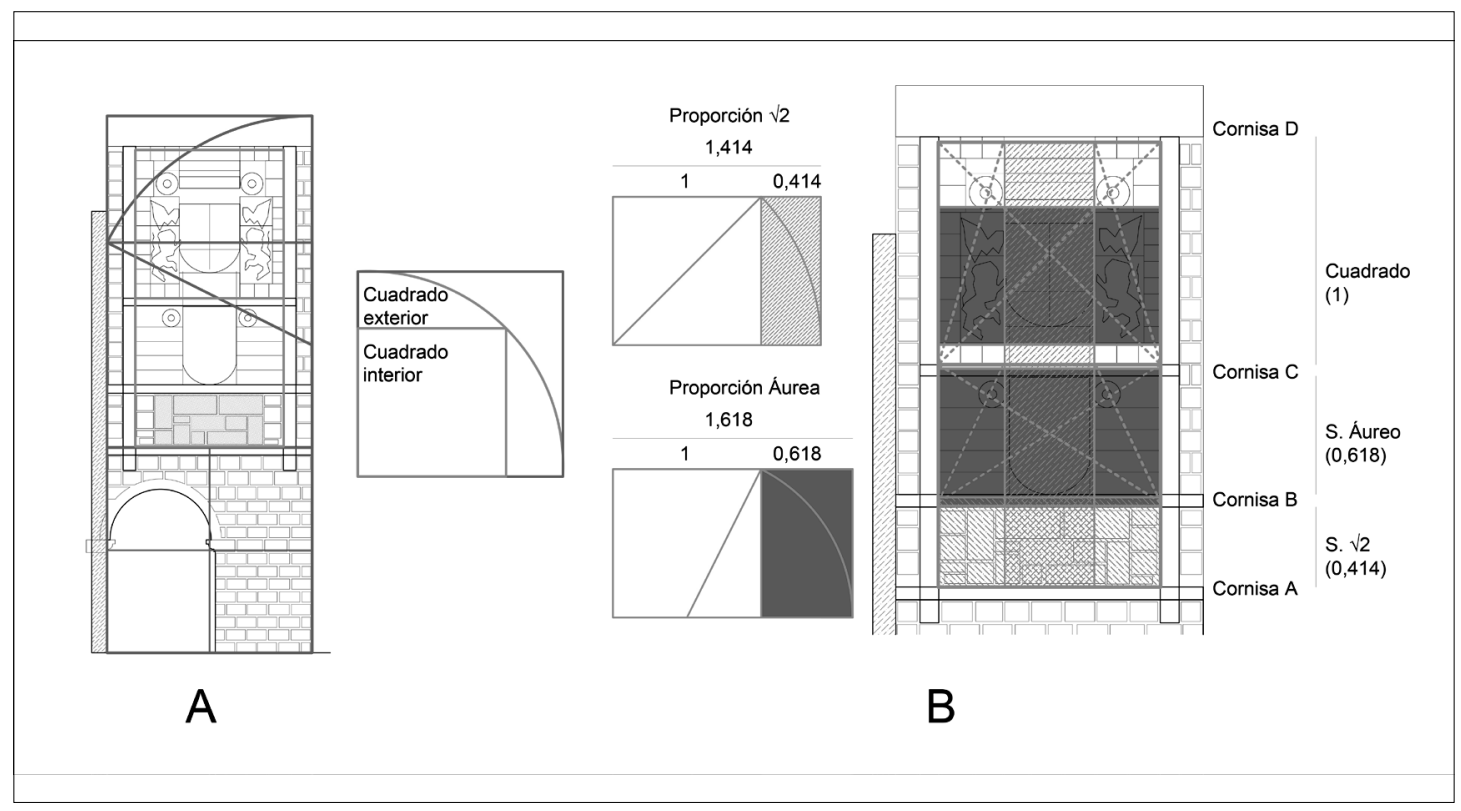

Fig. 6. Estudio de proporciones de la puerta de España (Daniel Domenech Muñoz).

39 DOMENECH MUÑOZ, Daniel, Estudio sobre la composición de la puerta de España de Orán (informe mecanografiado), 5 de noviembre de 2020. 
modelo con Felipe II, III y IV. Aparecen en lugar preminente Castilla y León, Aragón y las Dos Sicilias, Granada, Austria, Jerusalén, Flandes, Tirol, Borgoña Valois, Borgoña Antigua y Bravante, y Portugal, aunque falta Navarra.

Se encuentra timbrado por una corona real, aunque no puede descartarse que en este elemento falte un fragmento superior que podría darle otro significado y cronología (tal vez ese primer contexto cronológico imperial del que hemos hablado), quedando la corona poco proporcionada en su tamaño respecto al conjunto del escudo. Orlado con el Toisón de Oro, no presenta las características columnas de Hércules y en su lugar se disponen dos leones rampantes ${ }^{40}$. Finalmente lo remata el águila bicéfala imperial, lo que podría vincular aparentemente su fábrica a la época del emperador Carlos, aunque la existencia de las armas de Portugal lo sitúa claramente en una fecha posterior a 1581 . $\mathrm{Al}$ respecto de estas aparentes ambigüedades, Eugène Cruck apuntaba que el escudo se debía a una reforma realizada en época de Felipe II sobre otro anterior del emperador Carlos ${ }^{41}$. De todas formas, señalaremos que no es excepcional que el blasón de Felipe II aparezca con el águila bicéfala, aunque es mucho más habitual que fuera un águila con una sola cabeza. En este sentido, resulta significativo el escudo que este monarca le entrega a la población de El Ciego de La Rioja, una mezcla de las armas de ambos.

Manuel Fuertes de Gilbert ${ }^{42}$ lo adscribe a la época de Felipe II (o de Felipe III) y señala que no fue hasta las Cortes de Tomar de 1581 cuando este monarca asumió la soberanía portuguesa y las armas de este reino, opinión que comparte Juan Cartaya Baños ${ }^{43}$.

Para el escudo, en su estado actual, Fuertes de Gilbert descarta una cronología correspondiente al reinado de Carlos V, y justifica sus peculiaridades (la corona, el águila o el propio Toisón) en que al ser elementos exteriores y paraheráldicos, su forma podía ofrecer representaciones variables, cosa que no ocurriría en los momentos imperiales. Por último, señala que de

40 No podemos olvidar que Orán, نارo [Wahrān], significa león, y que el escudo de esta ciudad en el siglo XVIII consistía en un león rampante.

${ }^{41}$ CRUCK, Eugène, Oran et les témoins, opus cit.

42 Manuel Fuertes de Gilbert y Rojo, Real Academia Matritense de Heráldica y Genealogía.

43 Juan Cartaya Baños, Grupo de Investigación sobre Andalucía y América Latina de la Universidad de Sevilla. haber sido un escudo del césar Carlos estos motivos hubieran sido mucho más aparatosos, con corona imperial, Toisón destacado y con las dos columnas en lugar de leones.

De menor tamaño es el segundo escudo de la portada, situado bajo el anterior, y cuyo análisis resulta bastante más complicado debido al mal estado de conservación, que ya era perceptible en fotografías de finales del siglo XIX y refrendaban las descripciones de la época.

En la parte posterior del cubo prismático que compone la puerta existe un tercer escudo de piedra, muy deteriorado, pero del que podemos aportar una hipótesis. Sobre la base de fotografías antiguas se aprecia la elaboración de un blasón cuartelado en aspa, relacionable a todas luces con el del marqués de Ardales (cuartelado en aspas, con calderas de oro y sierpes en las asas, y en los huecos cinco armiños negros a cada lado). Debe recordarse al respecto que, el marqués de Ardales, fue gobernador de Orán a principios del siglo XVII y, a su vez, responsable de la última fábrica de la portada en cuestión.

\section{Conclusiones}

La puerta de España de Orán es, sin duda, una de las portadas más monumentales de todas las realizadas en el norte de África durante el siglo XVI. El análisis de las fuentes y el estudio del monumento nos ha permitido trazar un marco cronológico que liga su imagen actual con las intervenciones llevadas a cabo entre los reinados de Felipe II y III, aunque sobre una anterior estructura compositiva de la época del emperador Carlos V. Por esta razón, la sucesión de obras ha generado un conjunto de cierta complejidad con patentes interrogantes que deberían ser contestados a partir de una futura y deseable restauración científica del monumento, que permitiera documentar las distintas fases y las modificaciones efectuadas. Su valor como monumento histórico y la importancia de sus valores estéticos la convierten en una obra de enorme relevancia, en tanto conjuga a la perfección el uso de algunas formas del Renacimiento con el deseo de los monarcas españoles de reflejar su prestigio en el norte de África. 